\title{
A Defined Medium for Haemophilus influenzae and Haemophilus parainfluenzae
}

\author{
BY L. O. BUTLER \\ Bacteriology Department, St George's Hospital Medical School, London, S.W. 1
}

(Received 20 April 1961)

\begin{abstract}
SUMMARY
A defined medium is described for the growth of Haemophilus influenzae and H. parainfiuenzae which can be used either as a liquid medium or solidified with agar. The purine and pyrimidine, vitamin, amino acid and mineral salt requirements for three strains have been analysed.
\end{abstract}

\section{INTRODUCTION}

Although a chemically defined medium has been described for Haemophilus parainfluenzae (Herbst \& Snell, 1949; Herbst \& Glinos, 1955), no such medium has been available for $H$. influenzae. This has retarded progress in the study of the genetics of transformable haemophilus strains since biochemical markers could not be studied. It was the possible application in genetic studies that prompted the search for a defined medium for $\boldsymbol{H}$. influenzae. Since the start of this investigation Talmadge \& Herriott (1960) described a modification of the tissue culture medium M-199 (Morgan, Morton \& Parker, 1950) which allowed the growth of $H$. influenzae. It was felt, nevertheless, that further study was needed and that perhaps a simpler defined medium might be devised.

Organisms

METHODS

Haemophilus influenzae strain Rd of Alexander \& Leidy (1953), a rough mutant from a wild Pittman type d, and of known transformability; $H$. influenzae strain RdTr, a strain derived from strain Rd by Dr P. Schaeffer, resistant to streptomycin, erythromycin and novobiocin; and $H$. parainfluenzae strain FID, isolated from a human throat by $\mathrm{Dr}$ H. E. Alexander; these will be referred to in the text as strains Rd, RdTr and FID. All strains were maintained on slopes of chocolate agar in cotton-wool plugged test tubes kept at $37^{\circ}$.

\section{Stock culture medium}

Tryptone (Difco) was dissolved in glass distilled water at $20 \mathrm{~g}$. together with $\mathrm{NaCl}$. at $10 \mathrm{~g} . / 1$. The $\mathrm{pH}$ was brought to about 3 with $\mathrm{HCl}$ and activated charcoal added to give a $0: 2 \%(w / v)$ suspension. The mixture was allowed to stand with occasional. shaking for $15 \mathrm{~min}$. and then filtered. The filtrate was adjusted to $\mathrm{pH} 7.5$ and agar (Davis) added to give a $2 \%(\mathrm{w} / \mathrm{v})$ solution. The medium was stored at this stage. When required, oxalated horse blood was added to give a $5 \%(v / v)$ mixture to the molten medium cooled to about $80^{\circ}$, and the blood allowed to turn to a chocolate colour, heated further in a water bath when necessary. The medium was then dispensed as slopes or plates. 
Solutions used in the development of the defined medium

Haematin solution. A stock solution of haematin (Roche Products Ltd.) was prepared as follows: $50 \mathrm{mg}$. haematin were mixed with $12.6 \mathrm{ml} .0 .5 \mathrm{M}-\mathrm{Na}_{2} \mathrm{HPO}_{4}$, heated to dissolve, and $86 \mathrm{ml}$. glass distilled water $+1.6 \mathrm{ml} . \mathrm{M}-\mathrm{KH}_{2} \mathrm{PO}_{4}$ added. The solution was sterilized by autoclaving at $115^{\circ}$ for $10-15 \mathrm{~min}$. One $\mathrm{ml}$. of the stock solution was used in $21 \mathrm{ml}$. of medium, i.e. a final concentration of $2.4 \mathrm{mg}$. haematin/100 ml. medium.

Coenzyme 1 solution. Diphosphopyridine nucleotide (Sigma Chemical Co.) was dissolved in glass distilled water to $1 \mathrm{mg} . / \mathrm{ml} ., 0.06 \mathrm{ml}$. of this solution was used in $21 \mathrm{ml}$. medium, i.e., a final concentration of $0.3 \mathrm{mg}$. DPN/100 ml.

Glucose-salts solution 1 . The solution consisted of $5 \cdot 0 \mathrm{~g}$. glucose; $17 \cdot 5 \mathrm{~g} . \mathrm{K}_{2} \mathrm{HPO}_{4}$; 5.0 g. $\mathrm{KH}_{2} \mathrm{PO}_{4} ; 1.056$ g. $\mathrm{Na}_{3}$ citrate. $5 \mathrm{H}_{2} \mathrm{O} ; 0.25 \mathrm{~g} . \mathrm{MgSO}_{4} \cdot 7 \mathrm{H}_{2} \mathrm{O} ; 2.5 \mathrm{~g} .\left(\mathrm{NH}_{4}\right)_{2} \mathrm{SO}_{4}$ in $100 \mathrm{ml}$. glass distilled water. The mixture was sterilized by autoclaving at $115^{\circ}$ for $10 \mathrm{~min}$., and $0.8 \mathrm{ml} . / 21 \mathrm{ml}$. medium was used.

Glucose-salts solution 2 . The solution consisted of 20 g. glucose; $17 \cdot 5 \mathrm{~g} . \mathrm{K}_{2} \mathrm{HPO}_{4}$; 5.0 g. $\mathrm{KH}_{2} \mathrm{PO}_{4} ; 0.105 \mathrm{~g}$. $\mathrm{Na}$ acetate; $0.25 \mathrm{~g} . \mathrm{MgSO}_{4} .7 \mathrm{H}_{2} \mathrm{O} ; 0.5 \mathrm{~g} . \mathrm{Ca}\left(\mathrm{NO}_{3}\right)_{2} ; 0.006 \mathrm{~g}$. $\mathrm{FeSO}_{4} \cdot 7 \mathrm{H}_{2} \mathrm{O} ; 0 \cdot 625 \mathrm{~g} . \mathrm{NaHCO}_{3}$ in $100 \mathrm{ml}$. glass distilled water. The mixture was sterilized by autoclaving at $115^{\circ}$ for $10 \mathrm{~min}$.; $0.4 \mathrm{ml}$. was used per $21 \mathrm{ml}$. medium.

Yeast extract solution. Yeast extract (Difco) was dissolved in glass distilled water to make a $10 \%(\mathrm{w} / \mathrm{v})$ solution, and sterilized by Seitz filtration.

Zeo-carb treated yeast extract. Yeast extract solution $(10 \%(\mathrm{w} / \mathrm{v}))$ was treated with Zeo-carb 225/H in the proportion of $1 \mathrm{~g}$. resin/3 ml. solution for 20-25 min. with occasional shaking, the mixture then centrifuged, and the supernatant fluid removed and sterilized by Seitz filtration.

Yeast extract ash solution. Yeast extract was ignited repeatedly to constant weight in a platinum dish. The ash was dissolved in concentrated nitric acid, glass distilled water added and the solution adjusted to $\mathrm{pH}$ 6.5. Further distilled water was added to give a concentration equivalent to $10 \%(\mathrm{w} / \mathrm{v})$ of the initial weight of yeast extract before ashing. The solution was sterilized by autoclaving at $115^{\circ}$ for $10 \mathrm{~min}$; $; 0.5 \mathrm{ml}$. of this solution was used in $21 \mathrm{ml}$. medium.

Agar. New Zealand agar (Davis) at $3 \%(\mathrm{w} / \mathrm{v})$ in glass distilled water was sterilized by autoclaving. The molten agar was mixed with the other medium constituents in $\mathbf{2 5} \mathrm{ml}$. screw-capped bottles and then poured in plates, the final agar concentration being $1 \%(w / v)$.

\section{Evaluation of medium}

Suspensions of the organisms were made in normal saline and a loopful spread over a segment of a plate of medium. After incubation at $87^{\circ}$ for $24 \mathrm{hr}$. and $40 \mathrm{hr}$. a visual assessment was made of the density and homogeneity of growth and of colony size. Assessment of growth in liquid cultures was made by a visual comparison of the turbidities.

\section{RESULTS}

It was decided to start from a non-defined medium which supported growth and which might lend itself to separation into its components. The basal solution contained haematin and DPN as indicated above, with $200 \mathrm{mg}$. crystalline bovine 
albumin (Armour Pharmaceutical Co. Ltd.) per $100 \mathrm{ml}$. medium, and either glucosesalts solution 1 or glucose-salts solution 2. To this mixture were added the other constituents to be studied, followed by the agar. The albumin requirement will be discussed later.

\section{Yeast extract}

Strain FID grew well on basal solution + glucose-salts solution 1 containing yeast extract at a final concentration of $0.25 \%(w / v)$ and above, and still gave small colonies with the yeast extract down to $0.05 \%(w / v)$. Strain Rd also grew but not as well, requiring $40 \mathrm{hr}$. to give colonies. A somewhat more luxuriant growth was obtained with strain FID on the addition of the 19 amino acids shown in column $(a)$ of Table 1, and the growth developed brown pigmentation. Strain Rd also grew better in the presence of the amino acids, forming dense white colonies with a more transparent rim, and causing a white precipitate to appear in the medium. These colonies were found to have a decreased requirement for haematin and were designated Rd1; the properties of this variant will be described elsewhere.

\section{Investigation of yeast extract constituents}

Diffusibility. When a sterile dialysis sheet (Visking) was placed over the medium containing double strength yeast extract, the sheet covered with an equal volume of basal solution + glucose-salts solution $1+$ amino acids, and the surface inoculated, strain Rd did not grow although strain FID gave pigmented colonies. This suggested that the activity given by the yeast extract which allowed growth of strain Rd was not dialysable. This point was not investigated further.

Effect of Zeo-carb treatment. Addition of yeast extract treated once with Zeo-carb to the basal solution + glucose-salts solution 1 at a final concentration equivalent to $0.25 \%(w / v)$ of untreated yeast extract gave decreased growth of strain FID even in the absence of added amino acids; strain RdTr behaved similarly but only when the concentration of the treated yeast extract was doubled. Strain Rd did not grow even in the presence of added amino acids. After the once-treated yeast extract had been autoclaved at $115^{\circ}$ for $10 \mathrm{~min}$., it lost the ability to support strain $R d T r$, and the growth of strain FID was further diminished. The addition of amino acids stimulated strain FID but had no effect on strain RdTr.

Treatment of the yeast extract three times with Zeo-carb followed by Seitz filtration or autoclaving resulted in a still further diminished ability to support strains FID and RdTr.

In summary, treatment of the yeast extract three times with Zeo-carb followed by autoclaving still permitted some growth of strains RdTr and FID in the absence of added amino acids. Strain Rd did not grow after such treatments of the extract. These findings suggested that, given a medium containing a full complement of amino acids and vitamins, the additional essential constituents provided by untreated yeast extract and removed by resin treatment might include purines, pyrimidines and metal ions. 


\section{Replacement of yeast extract}

The ability of medium containing treated yeast extract + basal solution + glucosesalts solution to support full growth of all three strains was restored by adding to it a solution of the ten vitamins shown in column (b) of Table 1, together with the nineteen amino acids and a solution of ash prepared from yeast extract. Later it was found that the Zeo-carb treated yeast extract itself could be replaced by a solution of purines and pyrimidines. Finally, the ash solution could be replaced by a solution of zinc sulphate.

Table 1. Mixtures of amino acids and of vitamins used as additions to the basal medium

(a)

\begin{tabular}{lc}
\hline \multicolumn{1}{c}{ Amino acid } & $\mathbf{m g} \cdot / \mathrm{l}$ \\
Glycine & $\mathbf{4 5 \cdot 7}$ \\
DL-Alanine & $\mathbf{4 5 \cdot 7}$ \\
DL-Valine & $\mathbf{1 3 7 \cdot 1}$ \\
L-Leucine & $\mathbf{1 3 7 \cdot 1}$ \\
DL-Isoleucine & $\mathbf{7 6 \cdot 2}$ \\
DL-Serine & $\mathbf{1 3 7 \cdot 1}$ \\
DL-Threonine & $\mathbf{6 8 \cdot 5 5}$ \\
DL-Aspartic acid & $\mathbf{1 3 7 \cdot 1}$ \\
L-Glutamic acid & $\mathbf{2 2 8 \cdot 5}$ \\
L-Arginine HCl & $\mathbf{4 5 \cdot 7}$ \\
L-Lysine (HCl) & $\mathbf{1 8 7 \cdot 1}$ \\
L-Cysteine HCl & $\mathbf{1 1 8 \cdot 9}$ \\
DL-Methionine & $\mathbf{6 8 \cdot 5 5}$ \\
Glutathione & $\mathbf{5 9 \cdot 5}$ \\
DL- $\beta$-Phenylalanine & $\mathbf{6 8 \cdot 5 5}$ \\
L-Tyrosine & $\mathbf{7 6 \cdot 2}$ \\
L-Tryptophan & $\mathbf{2 2 \cdot 9}$ \\
L-Histidine HCl & $\mathbf{5 6 \cdot 7}$ \\
L-Proline & $\mathbf{1 8 7 \cdot 1}$ \\
&
\end{tabular}

(b)

\begin{tabular}{lc}
\hline \multicolumn{1}{c}{ Vitamin } & $\mathbf{m g} \cdot /$. \\
$\begin{array}{l}\text { p-Aminobenzoic } \\
\text { acid }\end{array}$ & $\mathbf{8 \cdot 0}$ \\
Thiamine & $\mathbf{8 \cdot 0}$ \\
Biotin & $\mathbf{8 \cdot 0}$ \\
Ca pantothenate & $\mathbf{8 \cdot 0}$ \\
Choline chloride & $\mathbf{8 \cdot 0}$ \\
Folic acid & $\mathbf{0 . 8}$ \\
Inositol & $\mathbf{8 \cdot 0}$ \\
Nicotinic acid & $\mathbf{8 \cdot 0}$ \\
Pyridoxine HCl & $\mathbf{8 \cdot 0}$ \\
Riboflavin & $\mathbf{0 . 8}$
\end{tabular}

\section{Purine and pyrimidine requirements}

The purine and pyrimidine requirements were investigated by using the basal solution + glucose-salts solution $\mathbf{2}$ +amino acids and vitamins indicated above, together with glutamine + putrescine + yeast extract ash. The purines used were adenine, guanine and hypoxanthine, and the pyrimidines thymine, cytosine and uracil. The results obtained are summarized in Table 2 , from which it can be seen that the requirements of all three strains were met by the inclusion of only adenine, guanine and uracil. Strain Rd required adenine and uracil, whilst strain FID required guanine, although uracil, and to a lesser extent, adenine, stimulated growth. A detailed analysis of the requirements of strain $R d T r$ was not made, but it grew well on the mixture containing adenine, guanine and uracil. Neither thymine, cytosine nor hypoxanthine was required by any of the three strains.

\section{Table 2. Purine and pyrimidine requirements of three Haemophilus strains}

\begin{tabular}{llcc} 
Strain & \multicolumn{1}{c}{ Essential } & Stimulatory & Not required \\
Rd & Adenine, uracil & - & Thymine, cytosine, hypoxanthine, guanine \\
FID & Guanine & Uracil, adenine & Thymine, cytosine, hypoxanthine \\
RdTr & Grows well with adenine+guanine + uracil
\end{tabular}




\section{Vitamin requirements}

Of the ten vitamins listed in column $(b)$ of Table $1, p$-aminobenzoic acid, biotin, choline chloride, folic acid, inositol, nicotinic acid and riboflavin were not required by any of the strains. Table $\mathbf{3}$ gives the results for the remaining vitamins, and also for glutamine and putrescine. The latter substance was used because of the work of Herbst \& Snell (1949) in which putrescine was described as a growth factor for Haemophilus parainfluenzae. It can be seen from Table 3 that no added vitamin appeared to be essential for strain $R d$, although calcium pantothenate and thiamine were stimulatory, the former being replaceable by pyridoxine. Strains $\operatorname{RdTr}$ and FID both required pyridoxine, and were stimulated by pantothenate, although this could be replaced by thiamine for strain FID. Putrescine stimulated all three strains and glutamine was stimulatory for strain RdTr. It was observed that, in the presence of added biotin and folic acid, neither of which was required, strain $R d T r$ then showed a requirement for thiamine. The inclusion of pyridoxine, thiamine, calcium pantothenate, putrescine and glutamine therefore met the vitamin requirement of all three strains.

\section{Table 3. Vitamin requirements of three Haemophilus strains}

$\begin{array}{lc}\text { Strain } & \text { Essential } \\ \text { Rd } & - \\ \text { RdTr } & \begin{array}{c}\text { Pyridoxine (thiamine in } \\ \text { presence of biotin and } \\ \text { folic acid) }\end{array} \\ \text { FID } & \text { Pyridoxine }\end{array}$

\begin{tabular}{ll}
\multicolumn{1}{c}{ Stimulatory } & Not required \\
$\begin{array}{l}\text { Ca pantothenate, } \\
\text { putrescine, (pyridoxine in }\end{array}$ & $\begin{array}{c}\text { Biotin, folic acid, thiamine, } \\
\text { glutamine, pyridoxine }\end{array}$ \\
$\begin{array}{l}\text { Ca pantonce of Ca-pantothenate) } \\
\text { glutamine, putrescine }\end{array}$ & Biotin, folic acid \\
$\begin{array}{l}\text { Ca pantothenate, } \\
\text { putrescine (thiamine in } \\
\text { absence of Ca-pantothenate) }\end{array}$ & $\begin{array}{l}\text { Biotin, folic acid, thiamine, } \\
\text { glutamine }\end{array}$
\end{tabular}

\section{Mineral salts requirement}

The salts finally used are shown in Table 5.

$\mathrm{ZnSO}_{4}$. It was found that the yeast extract ash could be replaced by a suitable concentration of $\mathrm{ZnSO}_{4}$. The element $\mathrm{Zn}$ is a known constituent of some enzyme systems. At a concentration of $3.42 \mathrm{mg}$. $\mathrm{ZnSO}_{4} \cdot 7 \mathrm{H}_{2} \mathrm{O} / 100 \mathrm{ml}$. medium (0.0001 $\left.\mathrm{M}\right)$ the growth promoting effect was at least as good as that of the yeast extract ash at the concentration previously stated, but at lower concentrations of the zinc salt there was a rapid diminution of growth. This concentration of zinc represents approximately 1 part/2500. Zinc was spectroscopically undetected in the yeast extract ash but this concentration is below the limit of detection by this method in a sodium and potassium matrix.

$\mathrm{Na}$ acetate. This compound had no effect on strains $\mathrm{Rd}, \mathrm{RdTr}$ or FID. It was retained in the complete medium, however, because it was stimulatory to the growth of the variant Rdl referred to above, which was investigated simultaneously during the development of this medium.

$\mathrm{NaHCO}_{3}$. This was stimulatory to all three strains.

$\mathrm{FeSO}_{4}$. This was somewhat stimulatory to all three strains at $0.114 \mathrm{mg}$. $\mathrm{FeSO}_{4} \cdot 7 \mathrm{H}_{2} \mathrm{O} / 100 \mathrm{ml}$. medium $(0.000004 \mathrm{M})$, but was toxic at higher concentrations. 
Phosphates. At concentrations lower than $330 \mathrm{mg}$. $\mathrm{K}_{2} \mathrm{HPO}_{4} / 100 \mathrm{ml}$. medium $(0.019 \mathrm{M})$ and $94 \mathrm{mg}$. $\mathrm{KH}_{2} \mathrm{PO}_{4} / 100 \mathrm{ml}$. medium $(0.007 \mathrm{M})$ there was diminished growth.

$\mathrm{CaCl}_{2}$. When the medium contained crystalline bovine albumin, $\mathrm{CaCl}_{2}$ was not required to be added, but when the albumin was replaced by polyvinyl alcohol, then $\mathrm{CaCl}_{2}$ at a concentration of $6.75 \mathrm{mg} . / 100 \mathrm{ml}$. medium $(0.0006 \mathrm{M})$ was stimulatory.

$\mathrm{MnCl}_{2}$. This was not found to be necessary.

In general strains FID and RdTr were more sensitive to higher concentrations of salts than was strain $R d$; strain $R d T r$ was the most sensitive.

\section{Amino acid requirements}

Of the nineteen amino acids listed in column (a) Table 1, glycine, alanine, serine, threonine, methionine, proline and lysine could be omitted without decreased growth. Glutathione and cysteine were interchangeable, but better growth was given with glutathione. Table 4 gives a summary of the amino acid requirements for each strain. It will be noted that strain $\mathbf{R d}$ did not appear to have an essential requirement for any one amino acid, i.e. the omission of any one of the amino acids from the minimal mixture did not abolish growth.

Table 4. Amino acid requirements of three Haemophilus strains

\begin{tabular}{|c|c|c|c|}
\hline Strain & Essential* & Stimulatory & Not required \\
\hline $\mathbf{R d}$ & 一 & $\begin{array}{l}\text { Tryptophan, cysteine or glutathione, } \\
\text { histidine, tyrosine, arginine, aspartic } \\
\text { acid, glutamic acid, leucine, isoleucine, } \\
\text { phenylalanine, valine }\end{array}$ & $\begin{array}{l}\text { Lysine, glutathione or } \\
\text { cysteine, methionine, } \\
\text { alanine, glycine, proline, } \\
\text { threonine, serine }\end{array}$ \\
\hline FID & $\begin{array}{l}\text { Isoleucine, } \\
\text { valine }\end{array}$ & $\begin{array}{l}\text { Tryptophan, cysteine or glutathione, } \\
\text { histidine, tyrosine, arginine, aspartic } \\
\text { acid, glutamic acid, leucine, } \\
\text { phenylalanine }\end{array}$ & As for strain $R d$ \\
\hline RdTr & $\begin{array}{l}\text { Isoleucine, } \\
\text { leucine, } \\
\text { tyrosine }\end{array}$ & $\begin{array}{l}\text { Tryptophan, cysteine or glutathione, } \\
\text { aspartic acid, valine (histidine, arginine, } \\
\text { and phenylalanine not tested with } \\
\text { strain } \mathrm{RdTr} \text { ) }\end{array}$ & $\begin{array}{l}\text { Glutamic acid and as for } \\
\text { strain Rd }\end{array}$ \\
\hline
\end{tabular}

* Where omission of any one amino acid from the minimum mixture stopped growth.

\section{Albumin}

It had been observed that the strains used, Haemophilus parainfluenzae in particular, did not grow well in broth media unless albumin was also added, and it seemed likely that the albumin was acting as a protective colloid. Consequently, crystalline bovine albumin at a final concentration of $0 \cdot 19 \%(w / v)$ had been added to the defined medium throughout its development. It was found, however, that this concentration was having an inhibitory effect; by decreasing the concentration a peak of maximum growth was obtained at a final concentration of $0.019 \%(w / v)$, with a sharp decrease in growth at lower concentrations and a more gradual decrease at higher concentrations; the curve obtained is shown in Fig. 1. Such a result would be expected if the albumin indeed acted as an adsorbent, and an alternative was sought to take its place. Polyvinyl alcohol was tried, with some success. The curve obtained by plotting concentrations of polyvinyl alcohol against growth is also shown in Fig. 1, and it can be seen that it has the same form as that for albumin. The slope 
of the peak on the high concentration side is steeper and the growth was somewhat less than with albumin. However, at $64 \mathrm{mg}$. polyvinyl alcohol/100 ml. medium, the inclusion of $\mathrm{CaCl}_{2}$ at $6.7 \mathrm{mg} . / 100 \mathrm{ml}$. medium gave growth comparable to that on albumin.

The medium containing either albumin or polyvinyl alcohol proved very satisfactory for several weeks, but on repeating the experiment growth suddenly became poor and even failed completely. It is known that fatty acids may cling even to wellwashed glassware. For this reason, the effect of adding sodium oleate was investigated. It was found that growth could be restored in this way. In the presence of albumin, good growth was obtained with $1.92 \mathrm{mg}$. sodium oleate/100 ml. medium or

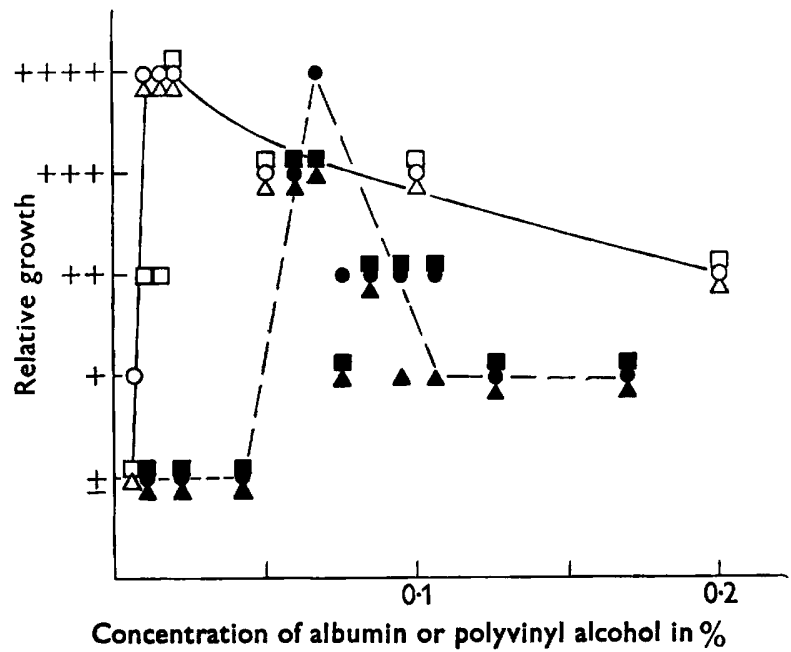

Fig. 1. Effect of crystalline bovine albumin (solid line and open points) and polyvinyl alcohol (broken line and solid points) on the growth of Haemophilus strains-Rd $(0,0)$, $\operatorname{RdTr}(\triangle, \Delta)$, and FID $(\square, \square)$.

in the presence of polyvinyl alcohol with $0.96 \mathrm{mg} . / 100 \mathrm{ml}$. medium. Strain Rd was affected only slightly by increase of oleate up to 25 -fold with albumin, or to 10-fold with polyvinyl alcohol, but strains FID and $R d T r$ were more sensitive. The latter strains were also more sensitive than strain $\mathrm{Rd}$ to lower concentrations of oleate. Oleate in fact completely replaced albumin or polyvinyl alcohol, best growth being obtained at a concentration of $0.48 \mathrm{mg}$. oleate $/ 100 \mathrm{ml}$. medium.

\section{Agar}

Agar was added to give a final concentration of $1 \%(w / v)$. Unwashed New Zealand (Davis) agar gave the same results when compared with New Zealand agar which had been washed $48 \mathrm{hr}$. in distilled water, and with Noble (Difco) agar.

The medium finally evolved, therefore, had the composition given in Table 5 . The medium was prepared by mixing appropriate volumes of several solutions containing either mixtures of various substances or single components. The table shows the $\mathrm{pH}$ of the stock solutions, and whenever possible these were adjusted to about $\mathbf{p H} 7$. Where no $\mathrm{pH}$ is indicated, no adjustment was made.

Viable counts (Miles \& Misra, 1938) were carried out with suspensions of each 
strain, comparing the counts obtained on the defined solid medium containing albumin or polyvinyl alcohol with those obtained on chocolate Tryptone agar. The counts obtained were similar, and showed that the defined media were equal to the chocolate agar in giving growth from inocula of 1 to 10 organisms. Such growth could not consist of selected mutants only. The colonies on the defined medium were somewhat smaller than those obtained on the chocolate tryptone agar and needed incubation for $86 \mathrm{hr}$. before counting.

Table 5. Composition of chemically defined medium for certain strains of Haemophilus influenzae and $\mathrm{H}$. parainfluenzae

Except where indicated, constituents were sterilized by autoclaving at $115^{\circ}$ for $10-15$ min.

\begin{tabular}{|c|c|c|c|c|c|}
\hline Substance & mg./l. & $\begin{array}{c}\mathrm{pH} \text { of } \\
\text { stock } \\
\text { solution }\end{array}$ & Substance & mg./l. & $\begin{array}{l}\text { pH of } \\
\text { stock } \\
\text { solution }\end{array}$ \\
\hline $\begin{array}{l}\text { DL-Valine } \\
\text { L-Leucine }\end{array}$ & $\begin{array}{l}137 \cdot 1 \\
137 \cdot 1\end{array}$ & $\begin{array}{l}6 \cdot 9 \\
6 \cdot 9\end{array}$ & Glucose & $3810 \cdot \theta$ & \\
\hline DL-Isoleucine & $76 \cdot 2$ & 6.9 & $\mathrm{~K}_{2} \mathrm{HPO}_{4}$ & $3300 \cdot 0$ & \\
\hline DL-Aspartic acid & $137 \cdot 1$ & 6.8 & $\mathrm{KH}_{2} \mathrm{PO}_{4}$ & $940 \cdot 0$ & \\
\hline L-Glutamic acid & 228.5 & 6.8 & $\mathrm{ZnSO}_{4} \cdot 7 \mathrm{H}_{2} \mathrm{O}$ & $\mathbf{3 4 . 2}\}$ & $7 \cdot 6$ \\
\hline L-Arginine $\mathbf{H C l}$ & $45 \cdot 7$ & 6.8 & Na acetate & $41 \cdot 9$ & \\
\hline DL- $\beta$-Phenylalanine & $68 \cdot 55$ & $6 \cdot \theta$ & $\mathrm{NaHCO}_{3}$ & 225.0 & \\
\hline L-Tyrosine* & $76 \cdot 2$ & 6.9 & $\mathrm{MgSO}_{4} \cdot 7 \mathrm{H}_{2} \mathrm{O}$ & $180 \cdot 0$ & \\
\hline L-Tryptophan* & $22 \cdot 9$ & $6 \cdot \boldsymbol{9}$ & $\mathrm{FeSO}_{4} .7 \mathrm{H}_{2} \mathrm{O}^{*}$ & $1 \cdot 14$ & \\
\hline L-Histidine $\mathbf{H C l}$ & 56.7 & 6.9 & $\mathrm{NaCl}$ & $8000 \cdot 0$ & \\
\hline $\begin{array}{l}\text { L-Cysteine } \mathbf{H C l}^{*} \\
\text { or }\end{array}$ & $118 \cdot 9$ & & & & \\
\hline Glutathione* & $\mathbf{5 9 \cdot 5}$ & & Na oleate & 4.8 & \\
\hline $\begin{array}{l}\text { Adenine } \\
\text { Guanine } \\
\text { Uracil }\end{array}$ & $\begin{array}{l}9.5 \\
0.95 \\
0.95\end{array}$ & $\begin{array}{l}6 \cdot 5 \\
2 \cdot 0 \\
6 \cdot 5\end{array}$ & Agar & 10,000 & \\
\hline $\begin{array}{l}\text { Pyridoxine } \mathrm{HCl}^{*} \\
\text { Thiamine* } \\
\text { Ca pantothenate* } \\
\text { Glutamine* } \\
\text { Putrescine* }\end{array}$ & \begin{tabular}{r|}
$8 \cdot 0$ \\
$8 \cdot 0$ \\
$8 \cdot 0$ \\
$300 \cdot 0$ \\
$2 \cdot 98$
\end{tabular} & $\begin{array}{l}7 \cdot 1 \\
7 \cdot 1 \\
7 \cdot 1\end{array}$ & & & \\
\hline $\begin{array}{l}\text { Haematin } \\
\text { Coenzyme I* }\end{array}$ & $\begin{array}{r}23 \cdot 8 \\
2 \cdot 9\end{array}$ & & & & \\
\hline
\end{tabular}

The defined medium without agar and with albumin allowed growth of all three strains, but only strains $R d$ and RdTr grew in liquid medium containing polyvinyl alcohol (but no oleate). This suggests that while crystalline bovine albumin or polyvinyl alcohol $+\mathrm{CaCl}_{2}$ are satisfactory alternatives for an agar solidified medium only albumin should be used for liquid medium. The addition of oleate to the albumincontaining medium enhanced growth, particularly that of strains Rd and FID. Oleate without albumin gave somewhat less growth than with albumin.

Five other strains of Haemophilus obtained from the National Collection of Type Cultures (NCTC) were tested for growth on the solid medium. Haemophilus influenzae NCTC 4560 and $H$. parainfluenzae NCTC 4101 grew on both the albumin-containing medium and the polyvinyl alcohol-containing medium, whilst $H$. canis NC'TC 1659 grew on the albumin-containing medium only. H. aegyptius NCTC 8502 and H. haemolyticus NCTC 8479 did not grow on either medium. The use of oleate, however 
(with or without albumin), allowed growth of the $H$. haemolyticus and also of two isolates of $H$. influenzae recently obtained, one from an eye swab and the other from a specimen of sputum. The $\boldsymbol{H}$. aegyptius strain was not tried on the oleate-containing medium as it was not available at the time of those experiments.

\section{DISCUSSION}

These results show that the nutritional difference between Haemophilus influenzae and $H$. parainfluenzae is not simply that the former is dependent on added haematin, since differences also occur between the two species in their amino acid, vitamin, purine and pyrimidine requirements, and in their sensitivities to the action of protective colloids. The dependence of $H$. influenzae on haematin, taken together with other cultural characteristics, gives the impression that this species is likely to be more exacting in its nutritional requirements than $H$. parainfluenzae. However, the results were contrary to such a concept, since the growth of strain $\mathbf{R d}$ was not dependent on the presence of any one vitamin or amino acid (in the presence of other vitamin and amino acids), whereas that of strain FID was dependent on the presence of pyridoxine, isoleucine and valine. It is tempting to suggest that the need of strain RdTr for isoleucine, leucine and tyrosine is connected with the resistance of this organism to streptomycin, erythromycin and novobiocin.

The use of crystalline bovine albumin in a defined medium may be objected to. It seems probable that the albumin takes no part as a nutrient and acts only as an adsorbent of growth inhibitors and a substitute for it was sought. It was thought that charcoal would be too active, and indeed Brumfitt (1959) found that Haemophilus influenzae was inhibited by $0.5 \%(\mathrm{w} / \mathrm{v})$ charcoal although Bordetella pertussis grew better in its presence. Starch has been used by several workers (Hornibrook, 1939, 1940; Wilson, 1945; Farrell \& Taylor, 1945; Cohen \& Wheeler, 1946; Verwey, Thiele, Sage \& Schuchardt, 1949) but it.was thought that this might hydrolyse to give sugars which would interfere with the use of the medium in a study of the sugar reactions of the group. Talmadge \& Herriott (1960) included polyvinyl alcohol in their modified M-199 medium, and it seemed probable that it was used as a detoxifying agent. As the present results showed, polyvinyl alcohol allowed growth comparable to that obtained with albumin (in the presence of low concentrations of $\mathrm{Ca}$ ion), but the strains tested were more sensitive to small changes in the concentration of polyvinyl alcohol than they were to similar changes of albumin.

The ability of oleate to replace albumin and polyvinyl alcohol would suggest that oleate also plays a physical rather than a metabolic role. On the other hand, however, the possibility still remains that oleate is required as a metabolite, and it may well be that it performs both metabolic and adsorptive functions. The effective concentration of oleate was about one-twentieth of that of albumin, which might be explained if its micelle is larger than the albumin molecule. When in the presence of albumin, oleate was required at four times the concentration, indicating the expected combination with albumin resulting in loss of activity. It is of interest to note that a loss of activity was also seen in the presence of polyvinyl alcohol.

Comparison of the medium described above with that of Talmadge \& Herriott shows several differences. These authors used only seven amino acids but the constituents included biotin, choline chloride and inositol, which were not necessary for the strains used in the present work. Nucleosides, including thymidine, were used by 
Talmadge \& Herriott, whereas the free purines and pyrimidines were found sufficient in the medium described here and thymine was unnecessary. An interesting difference is that no added zinc ion was needed by the American authors; their medium also included triethanolamine, glycylglycine and Tween 80.

The defined medium described above for Haemophilus should now make it possible to study its metabolism and the genetic control of its metabolic processes.

Grateful thanks are due to Dr G. R. F. Hilson and Professor S.D. Elek for valuable suggestions. Thanks are also due to Dr J. F. Herringshaw for the spectroscopic analyses, and to Mr S. Williams and Miss R. Redman for technical assistance.

\section{REFERENCES}

Alexander, H. E. \& LeIDy, G. (1953). Induction of streptomycin resistance in sensitive Haemophilus influenzae by extracts containing desoxyribonucleic acid from resistant Haemophilus influenzae. J. exp. Med. 97, 17.

BRUMFTT, W. (1959). Some growth requirements of Haemophilus influenzae and Haemophilus pertussis. J. Path. Bact. 77, 95.

Cohen, S. M. \& Wheeler, M. W. (1946). Pertussis vaccine prepared from Phase-1 cultures grown in fluid medium. Amer. J. publ. Hlth, 36, 371.

Farrell, L. \& TAYlor, E. M. (1945). Notes on the production of Phase-1 pertussis vaccine in fluid medium. Canad. J. publ. Hlth, 36, 326.

Hersst, E. J. \& Glinos, E. B. (1955). An analysis of the putrescine requirement of Haemophilus parainfluenzae. J. biol. Chem. 214, 175.

Herbst, E. J. \& SNELL, E. E. (1949). The nutritional requirements of Haemophilus parainfluenzae 7901. J. Bact. 58, 379.

Hornibrook, J. W. (1939). Cultivation of Phase-1 Haemophilus pertussis in a semisynthetic liquid medium. Publ. Hlth Rep., Wash. 54, 1847.

HorNIBroor, J. W. (1940). Nicotinic acid as a growth factor for Haemophilus pertussis. Proc. Soc. exp. Biol., N.Y. 45, 598.

MrLes, A. A. \& MrSRA, S. S. (1938). Estimation of the bactericidal power of blood. J. Hyg., Camb. 38, 732.

Morgan, J. F., Morton, H. J. \& Parker, R. C. (1950). Nutrition of animal cells in tissue culture; initial studies on a synthetic medium. Proc. Soc. exp. Biol., N.Y. 73, 1.

Talmadge, M. B. \& Herrioti, R. M. (1960). A chemically defined medium for growth, transformation, and isolation of nutritional mutants of Haemophilus influenzae. Biochem. biophys. Res. Comm. 2, 203.

Verwey, W. F., Threle, E. H., Sage, D. N. \& Schuchardt, L. F. (1949). A simplified liquid culture medium for the growth of Haemophilus pertussis. J. Bact. 58, 127.

Wilson, R. J. (1945). Production of Phase-1 pertussis vaccine in casein hydrolysate broth. Canad. J. publ. Hith, 36, 321. 